\title{
A AMAMENTAÇÃO DE BEBÊS PRÉ-TERMO: UM CAMINHO POSSÍVEL PARA A CONSTRUÇÃO DA COMUNICAÇÃO*
}

\author{
THE PRETERM BABY'S BREAST-FEEDING: A POSSIBLE \\ PATHWAY FOR THE \\ COMMUNICATION CONSTRUCTION
}

Susana E. Delgado ${ }^{1}$

Marileuza Zorzetto ${ }^{2}$

DELGADO, S.E.; ZORZETTO, M. A amamentação de bebês pré-termo: um caminho possível para a construção da comunicação. Rev. Bras. Cresc. Desenv. Hum., São Paulo, 2003.

Resumo: O objetivo do presente trabalho foi verificar o conhecimento que as mães de filhos prétermo têm à respeito do aleitamento materno e da importância deste como forma de comunicação, descrevendo os sinais de vínculo e comportamentos comunicativos da díade mãe-bebê durante amamentação. Foram realizadas entrevistas com as mães e observação da amamentação. A amostra foi composta de 15 mães, com idades entre 20 - 25 anos, e seus bebês pré-termo, internados na UTI Neonatal. Os resultados quanto ao conhecimento das mães em relação ao aleitamento mostraram que a maioria tinha informações adequadas sobre o mesmo, sendo que as formas de comunicação mais observadas foram a expressão facial, o contato visual e o contato físico. Concluiu-se que a maioria das díades, apesar das dificuldades iniciais, consegue, por meio da amamentação, desencadear a experiência da comunicação e da vinculação mãe-bebê.

Palavras-chave: interação mãe-bebê; aleitamento materno; fonoaudiologia; bebês pré-termo.

\section{INTRODUÇÃO}

A partir do momento em que uma mãe leva, pela primeira vez, o recém-nascido $(\mathrm{RN})$ ao peito, ela passa a saber que as mensagens amorosas que acompanham a amamentação são tão importantes para o bem-estar do bebê quanto o próprio leite.

Desta forma, cada vez mais são criados programas de incentivo ao aleitamento materno exclusivo buscando-se, com isto, melhorar a qualidade de vida e a redução da morbidade e mortalidade infantil, principalmente quando se trata de prematuros de baixo peso. Tais programas possibilitam melhorar a evolução clínica dos bebês, quando hospitalizados por um período de tempo prolongado, muitas vezes antecipando a alta (PEREIRA, 1996).

De acordo com LOPES (1999), ainda dentro da UTI Neonatal, as mães são estimuladas a manter a lactação por intermédio de ordenhas, de modo a facilitar o aleitamento materno logo que a criança adquire condições clínicas. Importante enfatizar que manter a lactação é uma tarefa difícil. Quanto menor é o recém-nascido, mais tempo será necessário

1 Universidade Luterana do Brasil. Campus Canoas-RS. Fonoaudióloga. Docente do Curso de Fonoaudiologia. Mestranda em Saúde Coletiva. E-mail: sudel.ez@terra.com.br

2 Universidade Luterana do Brasil. Campus Canoas-RS. Curso de Fonoaudiologia. Fonoaudióloga.

* Artigo extraído do Trabalho de Conclusão de Curso de Fonoaudiologia, Universidade Luterana do Brasil, 2002: A comunicação entre mães de mais de 20 anos e seus bebês prematuros durante a amamentação. 
para ele atingir uma estabilidade clínica, e osinúmeros períodos de piora e melhora clínicasão causadores de estresse para a mãe, dificultando ainda mais a manutenção da lactação.

Conforme afirmam MARTINEZ e CAMELO (2001), pela presença constante das mães nas UTI's, especialmente pelo estímulo dado à ordenha de seu leite para a alimentação do seu pequeno pré-termo, tem sido possível estreitar os laços de união entre mãe e filho, sendo utilizada a técnica do Método Canguru como um recurso para se estimular o contato pele a pele.

A amamentação é a melhor forma de alimentação sob o aspecto nutricional. Além disso, favorece as necessidades afetivas pelo contato íntimo entre a díade, onde a troca de olhares, o choro, os toques e fala com o bebê estimulam o desenvolvimento da linguagem e o estabelecimento do vínculo.

$\mathrm{O}$ contato face a face é essencial para as interações harmoniosas entre a dupla mãe bebê. Comportamentos do bebê como olhar, emitir sons, sorrir e chorar são sinais que indicam quando eles estão disponíveis para interagir e quando devem alterar ou terminar a interação (BARCELLOS e col., 1996).

Faz parte da avaliação fonoaudiológica do recém-nascido verificar a qualidade do contato inicial entre a mãe e seu bebê. A formação de um vínculo adequado nos dias que se seguem ao nascimento é a primeira garantia de uma resolução favorável de futuras crises no desenvolvimento. Para o recém-nascido prematuro, enfermo, ou envolvido em condições sócio- econômicas adversas, a interação pode representar a diferença entre a negligência e maus tratos, e a possibilidade de uma infância saudável (GIACOMINI, 1991).

A mesma autora ressaltou que a prematuridade é uma experiência traumática para mãe e cerca o recém-nascido de déficit interacionais. Este pode ser pouco reativo ao rosto humano, aos estímulos visuais e auditivos; pode ser difícil de ser consolado, possuindo dificul- dades na área motora e pouca tolerância à estimulação excessiva que via de regra lhe é oferecida. Durante o aleitamento, deve-se observar se ocorre o contato olho a olho, que pode indicar dois sinais significativos de problemas na interação mãe-bebê: a ausência de estimulação tátil e da auditiva. Uma situação de dificuldade no vínculo pode envolver medidas como um adiamento da alta hospitalar, entre outras. A comunicação da mãe com seu filho passa a ser um intercâmbio: enquanto ela o alimenta ou responde a suas outras necessidades, como troca de fraldas, banho ou aconchego, o bebê responde com os seus próprios recursos, através de mímicas, vocalizações, sorrisos, choro, dormir ou mamar. Com isso, a relação entre mãe e filho torna-se um verdadeiro diálogo (MORIZOT, 1999; FINNIE, 2000).

As mesmas autoras relatam que, no momento da alimentação, quando a mãe conversa com alguém, o bebê pára de sugar ou altera seu ritmo de sucção, prestando atenção na mãe. A criança age tanto sobre a sua mãe por meio de seus olhares, sorrisos, mímicas, quanto a mãe sobre o seu bebê por meio de palavras, gestos e toques que possuem um efeito tranqüilizador. Um sistema de comunicação equilibrado entre a mãe e o bebê irá orientar e facilitar a intervenção da mãe com relação à criança e a conseqüente formação do vínculo, que vai se solidificando no desenrolar da interação.

Dentro deste marco, a atuação da Fonoaudiologia nas unidades de tratamento intensivo neonatal tem, cada vez mais, um papel fundamental em avaliar e incentivar o aleitamento materno visando o desenvolvimento dos órgãos fonoarticulatórios, favorecendo o estabelecimento da relação mãe-filho, fundamental ao desenvolvimento da linguagem (HERNANDEZ, 1996; XAVIER, 1996).

A presente pesquisa teve como objetivo verificar o conhecimento que as mães acima de 20 anos de filhos prematuros têm sobre aleitamento materno e comunicação; descrever as características sócio-demográficas de idade, 
escolaridade, renda e estado civil, que constituem fatores de risco para o vínculo; e descrever os comportamentos comunicativos da díade mãe-bebê no momento da amamentação, com a finalidade de auxiliar os profissionais de saúde a conhecer estes comportamentos para melhor promover e incentivar o desenvolvimento harmonioso do bebê, nos seus aspectos emocionais e comunicativos.

\section{MATERIAL E MÉTODO}

A pesquisa realizada foi do tipo observacional; descritiva; transversal; de grupo; prospectiva e contemporânea (GOLDIN, 1997).

A amostra foi composta por 15 mães, com mais de 20 anos de idade e bebês prétermos de ambos os sexos, internados na UTI neonatal do Hospital de Clínicas de Porto Alegre, nascidos no período de setembro a outubro de 2002. Foram estabelecidos como critérios de exclusão: bebês pré-termos com malformações de cabeça e pescoço; mães adolescentes; mães portadoras do vírus HIV positivo; e mães que não pudessem ou não desejassem amamentar por qualquer motivo.

Os instrumentos de avaliação e/ou coleta foram compostos por: uma ficha de coleta de dados do prontuário do paciente; informações sobre condições do bebê ao nascer e as atuais; ficha de entrevista com as mães, com questões fechadas e abertas (gravada e posteriormente transcrita) referente aos dados sóciodemográficos e sobre o conhecimento do aleitamento; e ficha de protocolo de observação dos sinais de vínculo mãe/bebê e da comunicação durante a amamentação (Anexo A).

A análise dos dados foi feita de forma estatística descritiva (quantitativa), utilizandose medidas de tendência central como média e limites máximos e mínimos, e qualitativa, por categorização das respostas às questões abertas, de forma a relacionar os dados coletados com a teoria consultada.
O projeto de pesquisa foi aprovado pelo Comitê de Ética do Grupo de Pesquisa e PósGraduação do Hospital de Clínicas de Porto Alegre.

\section{RESULTADOS E DISCUSSÃO}

\section{Caracterização da amostra}

No período de setembro a outubro 2002, nasceram 24 bebês pré-termo de mães com mais de 20 anos, na UTI neonatal do HCPA. Porém, a presente pesquisa foi realizada com a participação de 15 díades dado que 9 díades foram

excluídas da pesquisa com base nos critérios de exclusão anteriormente citados.

\section{Caracterização dos bebês}

A maioria dos bebês da pesquisa 10 (67\%) era do sexo masculino e 5 (33\%) eram do sexo feminino. Para o peso ao nascer, a média encontrada foi de 1996g; para o peso atual, a média encontrada de $2096 \mathrm{~g}$, e para a idade gestacional, a média encontrada foi de 35 semanas e 4 dias. A tabela 1 mostra estes dados:

Dos 15 bebês observados, 9 (60\%) fizeram uso de sonda como forma de alimentação, antes da via oral ser liberada. XAVIER (1996) e HERNANDEZ (1996) referem que os bebês prematuros precisam se alimentar por sonda, uma vez que se encontram em situações de gra-

Tabela 1. Dados de peso e idade gestacional dos bebês.

\begin{tabular}{lrrrrrr}
\hline & N & Mínimo Máximo Média & $\begin{array}{l}\text { Desvio } \\
\text { padrão }\end{array}$ \\
\hline $\begin{array}{l}\text { Peso ao } \\
\text { Nascer (g) }\end{array}$ & 15 & 910 & 3500 & $1.996,67$ & 691,20 \\
$\begin{array}{l}\text { Peso Atual (g) } \\
\begin{array}{l}\text { Idade Gestacional } \\
\text { (em semanas) }\end{array}\end{array} 15$ & 1490 & 3620 & $2.096,67$ & 572,78 \\
\hline
\end{tabular}


vidade, quando a utilização plena da via digestiva no momento em que o RN precisa ser mais bem nutrido, torna-se difícil. Devem, então, ser alimentados por vias alternativas, como a via parenteral ou via enteral, a fim de garantir sua sobrevivência. As mesmas autoras afirmam que o uso prolongado das vias alternativas de alimentação pode levar à inibição e/ou alterações dos reflexos orais, das estruturas do sistema sensório motor oral e de suas funções, prejudicando a amamentação. Portanto, este achado coincide com a literatura consultada.

Com respeito à alimentação no momento da observação, dos 15 bebês da pesquisa, 6 (40\%) faziam a alimentação exclusiva ao seio materno, 5 (33\%) faziam alimentação mista (pelo seio materno e mamadeira), 4 (27\%) faziam pelo seio materno e sonda. Este achado coincide com o de FOGO (2000) que, em seu estudo sobre orientação e incentivo ao aleitamento materno do recém-nascido prematuro, constatou que o uso de fórmulas lácteas oferecidas por mamadeira era freqüente. Embora PEREIRA (1996) refira que, devido à sua composição inigualável,

o leite humano é considerado a fonte nutricional preferida para os prematuros, principalmente pelas suas vantagens imunológicas e nutricionais, o uso complementar de alimentação com mamadeira é uma rotina ainda bastante difundida nos hospitais.

\section{Caracterização das mães}

Com referência à idade das mães entrevistadas, os dados da tabela 2 mostram que a maioria das mães, ou seja 9 (60\%), possuíam de 20 a 25 anos de idade.

Tabela 2. Idade da mãe.

\begin{tabular}{ccc}
\hline Idades & Freqüência & $\%$ \\
\hline $20-25$ anos & 9 & 60,0 \\
Mais de 30 anos & 4 & 26,7 \\
$26-30$ anos & 2 & 13,3 \\
Base & 15 & 100 \\
\hline
\end{tabular}

Das mães entrevistadas, 5 tinham primeiro grau incompleto (33\%), 4 primeiro grau completo (26\%), 3 segundo grau completo (20\%), 1 segundo grau incompleto (7\%), 1 das mães teve terceiro grau incompleto (7\%), e 1 mãe teve terceiro grau completo(7\%).

Referente aos dados do estado civil, das 15 mães entrevistadas, 10 eram casadas ou “ajuntadas”, conforme referiram na entrevista.

Com respeito à renda familiar das mães entrevistadas, a tabela 3 mostrou que a renda familiar de 33,3\% das entrevistadas estava entre $\mathrm{R} \$ 601,00$ e $\mathrm{R} \$ 1.200,00$, e $26,7 \%$ ganhavam mais de $\mathrm{R} \$ 1.200,00$. A população de baixa renda, pela sua dificuldade de ter acesso aos serviços de saúde, apresenta um maior número de partos prematuros (PREDOMÔNICO, 1998). Porém, os achados desta pesquisa apresentaram mães de renda familiar mais elevada do que 3 salários mínimos ( $\mathrm{R} \$ 600,00$ ), considerado como baixa renda, portanto, discordante da literatura. Os dados referentes a fatores demográficos, como baixa renda, idade, baixa escolaridade e estado civil são apontados, na literatura, como potenciais riscos para a prematuridade e o baixo peso ao nascer. Portanto, sua inclusão, neste estudo, justifica-se para verificar o perfil das mães pesquisadas.

\section{RESULTADOS PRINCIPAIS}

Foi constatado que 93\%, ou seja, 14 das mães entrevistadas receberam orientação sobre amamentação e que apenas 1 mãe não tinha recebido orientação. Em relação ao local

Tabela 3. Renda Familiar.

\begin{tabular}{ccl}
\hline Renda familiar & Frequiência & $\%$ \\
\hline$-200,00$ & 3 & 20 \\
$201,00-600,00$ & 3 & 20 \\
$601,00-1.200,00$ & 5 & 33,3 \\
$+1.200,00$ & 4 & 26,7 \\
Total & 15 & 100 \\
\hline
\end{tabular}


em que a mãe recebeu esta orientação sobre amamentação, 5 (33\%), mães referiram o prénatal, 5 (33\%) mães referiram UTI neonatal, e 4 (27\%) das 15 mães responderam receber estas orientações, após o parto, no quarto, sendo que 1 mãe não recebeu orientação sobre a amamentação, em nenhum momento.

KING (1991) e SILVESTRE (2002) afirmam que, ainda no pré-natal, a mãe deve ser esclarecida que, durante a amamentação, ela produz um hormônio (ocitocina) que ajuda na rápida contração do útero, evitando hemorragias pós-parto, anemias, bem como tornando a mulher menos vulnerável ao câncer de mama e útero, em função dos baixos índices de estrógeno neste período. Deve ser informada igualmente de que o início do aleitamento materno precoce facilita o aprendizado da suç̧ão.

De acordo com LAWRENCE (1996), é melhor preparar a amamentação muito antes do parto. As futuras mães deveriam refletir sobre a alimentação do filho durante o período prénatal, quando a gravidez está bem estabelecida. Deveriam realizar uma ou mais consultas prénatais para comentar sobre a amamentação e sobre outros aspectos da puericultura a respeito dos quais podem ter dúvidas. As consultas pré-natais também devem tratar de qualquer dúvida que as mães podem ter sobre o processo de produção do leite e sobre a capacidade de ter leite suficiente. Nestas consultas pré-natais, a gestante já pode iniciar leituras sobre a amamentação. No presente estudo, verificouse que das 15 mães entrevistadas, apenas 5 delas foram orientadas no pré-natal.

A maioria das mães, ou seja, 14 das 15 mães entrevistadas $(93,3 \%)$ realizavam visitas aos seus bebês todos os dias da semana. Como todas as mães estavam amamentando, a maioria delas comparecia todos os dias da semana para oferecer o seio materno, em algum horário do dia. De acordo com BARCELLOS e col. (1996), a atividade da mãe com seu bebê prematuro na UTI Neonatal pode ser um bom indicador de sua adaptação social ao bebê, assim como seu ajustamento emocional. Conforme as mesmas autoras, este dado contribui para a criação do vínculo mãe/bebê, pois quanto mais a mãe visita seu bebê prematuro, mais o conhece e identifica as suas necessidades, sendo que a separação precoce, freqüentemente vivida pelos bebês prematuros e por suas mães, é um fator de risco para a interação mãe-bebê.

Foi verificado que 7 (47\%) das mães entrevistadas utilizaram o Método Canguru e 8 mães referiram não o realizar. A metodologia Canguru foi implantada em 2000 em todas as UTIs Neonatais por iniciativa do Ministério da Saúde como um programa nacional que promove um atendimento humanizado ao recém-nascido de baixo peso. Esta preconiza o contato pele a pele precoce entre a mãe e seu o prematuro. Desta forma, a amamentação, que é um componente importante na atenção mãe-bebê, recebe enfoque especial, com uma abordagem direcionada às necessidades desse grupo específico (OLIVEIRA, 2001). Porém, no presente estudo, apenas $47 \%$ das mães fizeram uso deste método sugerindo que ainda não se está conseguindo atingir toda a população que necessitaria deste cuidado.

Perguntou-se às mães a sua opinião à respeito de o bebê tentar se comunicar: 10 mães (67\%) responderam que o bebê tenta se comunicar. AIMARD (1998) afirma que todo ser humano atento pode constatar a capacidade do bebê se comunicar, em maior ou menor grau, desde que possa ver no bebê um interlocutor e um ser cheio de múltiplas capacidades, à espera de progredir. OLIVEIRA e BUSSAB (1996) referem que o bebê, desde o nascimento, apresenta predisposição para estabelecer formas elementares de interação social. Uma mãe sensível aos sinais de bebê, que responde de forma contingente, estará promovendo o desenvolvimento harmonioso da criança. Essas autoras afirmam que, dentro de um nível de organização próprio, o bebê está equipado para interagir com os adultos cuidadores. Esta visão de prestação de cuidados como forma de interação torna-se fundamental. Assim, cuidar 
do bebê deixa de ser um ato mecânico e técnico, tornando-se uma forma de comunicação.

Na tabela 4, verifica-se o conhecimento que as mães com mais de 20 anos têm a respeito do aleitamento materno e das orientações recebidas sobre o mesmo. A maioria das entrevistadas respondeu que a forma de posicionar o bebê no seio materno e a pega no seio são as orientações mais lembradas.

XAVIER (1996) e ARONIS e FIORINI (2002) referem que o posicionamento dos bebês durante a amamentação é muito importante. O posicionamento do recém-nascido em supino, com a cabeça elevada num ângulo menor que $45^{\circ}$ graus, além de facilitar a pega do seio, evita que o leite desça para a tuba auditiva causando otites, o que pode prejudicar o desenvolvimento da percepção auditiva e, consequentemente, da linguagem.

A pega do seio também foi lembrada pelas entrevistadas e, de acordo com FOGO (2000) e CUNHA (2001), a dificuldade na pega do seio gera fissura ou rachaduras no mamilo. Devido a isto, é necessário que o bebê abocanhe todo o mamilo e parte da auréola porque, desta forma, o bico do peito toca o céu da boca e estimula a ação de sugar, evitando assim a fissura do mamilo que pode influir no desmame precoce.

A orientação quanto à estimulação do seio materno foi citada por 6 das 15 mães en-

Tabela 4. Orientações sobre amamentação mais lembradas.

\begin{tabular}{lcc}
\hline \multicolumn{1}{c}{ Tipos de Orientações } & Frequëncia & $\%$ \\
\hline Como posicionar o bebê & 8 & 53,3 \\
no seio materno & 7 & 46,6 \\
Pega adequada do seio & 6 & 40,0 \\
Estimulação do seio & 2 & 13,3 \\
Posição da língua & 2 & 13,3 \\
Importância de oferecer os dois seios & 2 & 13,3 \\
Cuidados com as mamas & 1 & 6,6 \\
Não recebi nenhuma orientação & 1 & 6,6 \\
Não lembro da orientação & &
\end{tabular}

Questões de múltipla resposta. trevistadas. Segundo SOUZA (2001), a ordenha da mama está indicada em vários casos. Em especial, quando o bebê é prematuro ou doente, é indicado realizar a ordenha para manter a lactação enquanto o bebê não mama. Este procedimento pode ser mantido como ordenha parcial antes das mamadas com o objetivo de instalar o fluxo de leite e facilitar a amamentação para o bebê.

As mães foram questionadas quanto a como elas percebiam a comunicação do bebê. A tabela 5 mostra as suas respostas.

Conforme a tabela 5, os sinais de comunicação mais percebidos foram o contato visual, seguido de gestos faciais e corporais, reação à voz materna e ao choro. Duas mães referiram não perceber comunicação, uma das mães referiu que o bebê era muito pequeno, portanto, não havia comunicação ainda entre eles, e uma das mães referiu não saber se existia comunicação.

O contato visual foi a resposta mais citada por 8 mães como forma de comunicação. Para MONTORO (1982) e BOLWBY (1990), o estímulo visual a que o recém-nascido mais reage é ao rosto humano, sendo que a atenção visual parece implicar em uma relação interpessoal, servindo como base para que o bebê possa acreditar em sua própria capacidade de olhar e ser olhado. O rosto da mãe coincide tão perfeitamente com o campo visual imediato que se tornam indissociáveis ver e ser visto.

Tabela 5. Percepção materna da comunicação do bebê.

\begin{tabular}{lcr}
\hline $\begin{array}{c}\text { Formas de comunicação } \\
\text { percebidas pelas mães }\end{array}$ & Freqüência & $\%$ \\
\hline Contato visual & 8 & 53,3 \\
Gestos corporais & 7 & 46,6 \\
Gestos faciais & 7 & 46,6 \\
Reação à voz materna & 6 & 40,0 \\
Choro & 2 & 13,3 \\
Bebê não se comunica é muito pequeno & 2 & 13,3 \\
Mãe não percebe comunicação & 1 & 6,6 \\
Não sei & 1 & 6,6 \\
\hline
\end{tabular}

Questōes de múltipla resposta. 
Em relação aos gestos corporais e faciais, 7 mães responderam que percebem a comunicação do bebê através dos gestos. CRAMER (1987) relata que o RN dispõe de uma organização considerável, apresentando uma performance motora ou perceptiva que usa para comunicar-se. Para GIACOMINI (1991), o fato de o prematuro não ser muito ativo faz com que a mãe perceba os gestos faciais e corporais como comunicação, deixando-as mais alertas às demandas do bebê. Na atual pesquisa, as mães conseguiram perceber os sinais de comunicação do bebê, mostrando um maior ou menor grau de vínculo e compreensão da situação que o prematuro enfrentava.

Para OLIVEIRA e BUSSAB (1996), os comportamentos organizados do bebê podem orientar e facilitar a intervenção da mãe sobre ele. A reação à voz materna foi outra forma de comunicação dos bebês, percebida por 6 das mães entrevistadas. Conforme KENNEL e KLAUS (1993) e BOWLBY (1990), os RN preferem a voz humana a sons produzidos por objetos e as vozes femininas às masculinas, confluindo com os achados da presente pesquisa.

Em relação ao choro, 2 mães responderam ser esta a forma de comunicação do bebê identificada por elas. Este dado concorda com MONTORO (1982) que afirma que o bebê nasce com a capacidade de chorar e o choro é um importante elemento de sinalização; quando ele chora é atendido e, em geral, a conseqüência previsível que se segue ao choro é um adulto que se aproxima e tenta apaziguá-lo, para cessar o choro.

Os resultados a seguir referem-se ao Protocolo de Observação da amamentação que foi adaptado do Protocolo "Newborn Screening and Intervention in the Context of Health Care" de Johnson, traduzido por Claudia XAVIER (1996). Por meio deste protocolo é possível observar e registrar o comportamento comunicativo da díade mãe-bebê, no momento da amamentação.
Das mães observadas, 9 (60\%) mantiveram contato visual durante todo o tempo da amamentação, 5 mães faziam contato eventual (33\%) e 1 das mães observadas, o seu bebê estava com os olhos vendados, dificultando com isso verificar a efetividade do contato visual. BARCELLOS e col. (1996) reforçam que o contato face a face é essencial para as interações normais entre a dupla mãe/bebê. KENNEL e KLAUS (1993) observaram que as mães que tinham um contato prolongado com seus prematuros, desde o nascimento, apresentavam um comportamento de olhar diferente quando alimentavam seus filhos, olhando-os mais insistentemente.

Já para XAVIER (1996), nem todas as mães de recém-nascido pré-termo (RNPT) apresentam contato de olho. Ressalta que este item, tão importante no processo de interação, muitas vezes demora para ocorrer com esta dupla. Com relação à mãe, esta pode estar chocada com a aparência do RN, com seu estado de saúde geral, utilização de aparelhos etc., donde não consegue olhar realmente para o filho. Estas afirmações concordam com os dados encontrados na atual pesquisa.

Das mães observadas nesta pesquisa, 9 (60\%) tiveram contatos físicos durante a mamada e 6 mães (40\%) não realizaram contato físico durante a amamentação. Para BARCELLOS (1996), os prematuros necessitam de adultos interessados e afetuosos, tocando-os e segurando-os e falando com eles. Idealmente estes adultos deveriam ser seus pais.

KENNEL e KLAUS (1993) comentam que as mães de recém-nascidos pré-termo se diferenciam das mães de recém-nascidos a termo quanto ao toque. As mães RNPT apresentam um toque inseguro, não tocam seus bebês e demoravam para pegá-los no colo, enquanto as mães de bebês a termo não apresentam esta característica. Este dado confirma resultados encontrados na presente pesquisa onde $40 \%$ das mães entrevistadas não tocavam seus bebês, mesmo no colo. 
Das 15 mães observadas, a maioria (73\%) conversava com o bebê durante a amamentação, e (27\%) não conversava com seus bebês. Este dado deve ser interpretado com cautela, uma vez que existem mães que verbalizam mais que outras, independentemente do comportamento do bebê. Deve-se observar o ambiente e verificar se ele não dificulta este procedimento de vocalização. A mãe precisa, algumas vezes, estar sozinha para sentir-se mais à vontade e "conversar" com seu bebê (XAVIER, 1996).

De todas as mães observadas, 12 mães seguravam o bebê firmemente, com confiança, durante a amamentação, 2 mães apresentaram dificuldade de manipulá-lo e 1 mãe segurava o seu bebê de forma frouxa. Para WINNICOTT (1999), o ato de segurar mal uma criança demonstra que a mãe não está preparada para realizar esta ação, principalmente quando se refere a mães de bebês pré-termo, e pode ser um indicativo de dificuldade de vinculação. Na presente pesquisa, a maioria das mães não apresentou este comportamento.

Do total de mães observadas, 12 mães sorriram para o bebê durante a amamentação, 2 mães apresentaram uma expressão sóbria ou pouca expressão facial durante a amamentação e uma delas apenas olhares rápidos. Segundo XAVIER (1996), o sorriso por parte da mãe de um prematuro demora para ocorrer. O sorriso é uma expressão de emoção que, geralmente, transmite alegria. A mãe de um RNPT demora para apresentar a emoção de alegria; ela consegue sorrir para o bebê quando percebe que o mesmo é um ser humano que apresenta determinados comportamentos e que reage a ela. Este dado concorda com os dados da pesquisa atual, onde a maioria das mães sorriu para o seu bebê quando este se encontrava em um estágio mais estável.

\section{CONCLUSÃO}

Os resultados da presente pesquisa apresentam um quadro em que a maioria das mães participantes tinha idade entre 20 a 25 anos, um baixo grau de escolaridade, casadas e renda familiar de mais de 3 salários mínimos.

A média da idade gestacional dos bebês foi de 35 semanas e 4 dias, média de peso ao nascer $1997 \mathrm{~g}$, sendo a maioria dos recém-nascidos de baixo peso. A maior parte dos bebês fez uso de sonda e recebeu alimentação mista (seio materno mais complemento).

Em relação à orientação sobre amamentação, a maioria das mães referiu tê-las recebido, sendo verificado que somente $33 \%$ foram orientadas no pré-natal. Constatou-se que uma das mães não recebeu orientação em nenhuma das situações. É válido lembrar que o período pré-natal é indicado como o melhor período de assimilação das informações e preparação para a maternidade, o que irá favorecer o aleitamento materno por mais tempo. Porém, não foi isto o observado na presente amostra.

As orientações mais citadas sobre a amamentação referiram-se à postura do bebê, à pega adequada do seio e à estimulação das mamas para manter a lactação. Todas elas são fundamentais para o sucesso do aleitamento e demonstram que as mães possuíam informações adequadas.

Os resultados do protocolo de observação mostraram que a maioria das mães apresentou comportamentos adequados propiciando a comunicação e o vínculo com o bebê. Embora com filhos prematuros, o momento da amamentação mostrou-se uma oportunidade de aproximação da díade.

Este estudo possibilita concluir que a amamentação oportuniza o desencadeamento da comunicação entre mãe-bebê, não sendo apenas um ato de nutrição, mas um meio facilitador do desenvolvimento de uma interação e de um vínculo sadios, especialmente importante no que se refere a bebês pré-termo. A Fonoaudiologia, neste contexto, deve assumir o seu papel de incentivador do aleitamento materno como uma forma de prevenção dos distúrbios da comunicação. 


\begin{abstract}
The objective of the present work was to verify the knowledge that mothers of preterm babies have about maternal breast-feeding and the importance of this as a form of communication, describing the bond signs and the communicative behaviors of the mother-baby dyad during breastfeeding. Data were collected by means of interviews carried out with the mothers and one observation of breast-feeding. The sample was composed of 15 mothers, with ages ranging between 20 and 25 years, and their preterm babies hospitalized in the Neonatal Intensive Care Unit. The results about mothers' knowledge regarding breast-feeding showed that the majority of them had adequate information, and the most evident forms of communication observed in them were the facial expression, the physical and visual contact. It was concluded that the majority of these mothers and babies, despite the initial difficulties can trigger, through breast-feeding, the experience of communication and the mother-baby bond.
\end{abstract}

Key-words: mother-baby interaction; breast-feeding; speech and language therapy; preterm babies.

\section{REFERÊNCIAS BIBILIOGRÁFICAS}

AIMARD, P. O surgimento da linguagem na criança. Porto Alegre: Artes Médicas, 1998.

ARONIS, E.A.; FIORINI, M.D.C. Aleitamento materno e alimentação na primeira infância sob enfoque fonoaudiológico. Disponível: <http:// www.ceaodontofono.com.br/ publicacoes/ ago00-aleitamento. html> Acesso em: Setembro, 2002, p.1-5.

BARCELLOS, A.P.; BENJAMIN, A.C.W.; BASSOLS, A.S. Considerações sobre a prematuridade e a interação mãe-bebê. Revista de Medicina ATM , Porto Alegre, 96 (1): 77-81, 1996.

BOWLBY, J. Apego. A natureza do vínculo. São Paulo: Martins Fontes, 1990.

CRAMER, B. A psiquiatria do bebê: uma introdução. In: BRAZELTON, B. A dinâmica do bebê. Porto Alegre: Artes Médicas, 1987. p.25-45.

CUNHA, V.L.O. A importância das funções orais. In: CUNHA, V.L.O. Prevenindo problemas na fala pelo uso adequado das funções orais: Manual de Orientação. São Paulo: Pró Fono, 2001. p.6-12.

FINNIE, N.R. A contribuição dos pais para o aprendizado inicial. In: FINNIE, N.R. O manuseio em casa da criança com paralisia cerebral. São Paulo: Manole, 2000. p.111-115.

FOGO, M. Programa de Orientação e Incentivo ao Aleitamento Materno do Recém-Nascido Prematuro. Revista CEFAC- Atualização Científica em Fonoaudiologia, São Paulo, Revinter, 2 (1): 81-89, 2000.

GIACOMINI, C. A interação mãe-bebê. In: MIURA, E. Neonatologia, princípios e práticas. Porto Alegre: Artes Médicas, 1991. p.91-92.
GOLDIM, J.R. Manual de iniciação à pesquisa em Saúde. Porto Alegre: Decasa, 1997.

HERNANDEZ, A.M. Atuação fonoaudiológica em neonatologia: Uma proposta de intervenção. In:

ANDRADE, R.F. Fonoaudiologia em berçário normal e de risco. São Paulo: Lovise, 1996. p.76-79.

KING, F.S. Como ajudar as mães a amamentar. Londrina, 2000. [Dissertação de Mestrado Universidade Estadual de Londrina].

KENNELL, J.H.; KLAUS, M.H. A família durante a gravidez. In: KLAUS, M.H.; KENNELL, J.H. Pais/bebê: a formação do apego. Porto Alegre: Artes Médicas, 1993. p.32-41.

LAWRENCE, R.A. La lactancia materna: Una guia para la profesión médica. $4^{\circ}$ ed. Madrid: Mosby IDOY Malibros, 1996. p.230-233.

LOPES, S. M. B. Organização de um programa de acompanhamento do recém-nascido de risco. In: LOPES, S.M.B; LOPES, J.M.A. Follow up do recém-nascido de alto risco. Rio de Janeiro: MEDSI, 1999. p.55-68.

MARTINEZ, E.M.; CAMELO, J.S.J. Alimentação do recém-nascido pré-termo. J. Pediatr. 77(Supl.1): 32-40, 2001.

MONTORO, G. Vínculo mãe-filho: aqui nasce a capacidade de amar. Revista Psicologia Atual, São Paulo, 26: 29-32, 1982.

MORIZOT, R. A relação mãe-bebê e suas implicações no desenvolvimento infantil. Fonoaudiologia brás, 2(2): 22-26, julho, 1999.

OLIVEIRA, N.G.S.; BUSSAB, V.S.R. Comportamentos comunicativos do bebê como parceiro ativo na interação. Revista Brasileira de Crescimento e Desenvolvimento Humano, São Paulo, 6(1/2): p.34-38, 1996.

OLIVEIRA, N.D. A atenção humanizada ao recémnascido de baixo peso (Método Canguru) e a amamentação. In: REGO, J.D. Aleitamento materno. São Paulo: Atheneu, 2001. p.401-408. 
PEDROMÔNICO, M.R.M. O bebê atendido na Unidade de Terapia Intensiva: A imagem do corpo. In:

BASSETO, M.C.; BROCK, R., WAJNSZTEJN, R.

Neonatologia: um convite à atuação fonoaudiológica. São Paulo: Lovise, 1998. p.343-356.

PEREIRA, G.R. Alimentação do recém nascido. In: POLIN, R.A.; YODER, M.C.; BURG, F.D. Neonatologia prática. Porto Alegre: Artes Médicas, 1996. p.101-102.

SILVESTRE, S.R.P. Amamentação: Qualidade de vida aos bebês. Disponível: <http:// www.ceaodontofono.com.br/arquivos/jan02> html. Acesso em: janeiro 2002, p.1-2.
SOUZA, I.E.O. Ordenha do leite: como, quando e por quê fazê-la. In: REGO, J.D. Aleitamento materno. São Paulo: Atheneu, 2001. p.279-288.

WINNICOTT, D.W. Os bebês e suas mães. São Paulo: Martins fontes, 1999.

XAVIER, C. Atuação fonoaudiológica em berçário: Aspectos teóricos e práticos da relação mãebebê. In: ANDRADE, R.F. Fonoaudiologia em berçário normal e de risco. São Paulo: Lovise, 1996. p.101-126.

Recebido em 18/02/2003

Modificado em 14/03/2003

Aprovado em 21/03/2003

\section{ANEXO A \\ OBSERVAÇÃO DOS SINAIS DE VÍNCULO MÃE/BEBÊ E DE COMUNICAÇÃO DURANTE A AMAMENTAÇÃO}

1) Bebê mantém estado de alerta:

( ) $\operatorname{sim}(\quad)$ não

2) Mantém contato visual durante a mamada:

( ) mantém contato todo o tempo

( ) faz contato eventual

( ) ausência de contato visual

3) Mantém contato físico:

( ) toques maternos durante a mamada

( ) ausência de toques

4) Mãe conversa com o bebê durante a mamada? ( ) $\operatorname{sim}($ ) não

5) Modo de a mãe segurar o bebê:

( ) firme, com confiança

( ) com dificuldade de manipular

( ) de maneira frouxa

6) Expressão facial da mãe durante a mamada:

( ) sorri para o bebê

( ) expressão sóbria, pouca expressão facial

( ) olhares rápidos, vagos
7) Expressão oral durante a mamada:

( ) fala com o bebê carinhosamente

( ) pouca verbalização

( ) nenhuma verbalização

8) Reforço verbal materno:

( ) fala positivamente sobre o bebê

( ) faz comentários inapropriados ou negativos com relação ao bebê

( ) não faz nenhum comentário sobre o bebê.

9) Identificação das necessidades:

( ) reconhece as necessidades do bebê e responde a elas, sente-se bem ao reconhecer e satisfazer as necessidades/ desejos do bebê

( ) demonstra incerteza com relação ao significado das pistas dadas pelo bebê

( ) demonstra despreocupação com as necessidades do bebê, respondendo de forma inapropriada as necessidades do mesmo 